\title{
Peertechz
}

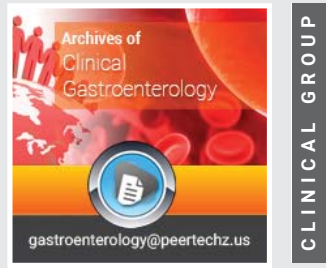

\section{Unusual cause of acute}

\section{abdominal pain: Eosinophilic colitis case report and review of the literature}

\section{S Bouchrit*, A Ait Errami, Z Samlani, S Oubaha and K Krati}

Department of Gastroenterology, CHU Mohamed VI, Marrakech, Morocco

Received: 17 February, 2021

Accepted: 05 March, 2021

Published: 06 March, 2021

*Corresponding author: S Bouchrit, Department of Gastroenterology, CHU Mohamed VI, Marrakech, Morocco, E-mail: sarah.bouchrit2@gmail.com

Keywords: Eosinophilic colitis; Hyper-eosinophilia; Allergy; Corticotherapy

https://www.peertechzpublications.com

\section{Check for updates}

\section{Abstract}

Eosinophilic colitis is an exceptionally rare condition, the clinical symptoms is polymorphic and non-specific. The diagnosis is based on the grouping of endoscopic and essentially histological, clinical arguments. We describe the case of a male patient with eosinophilic colitis revealed by bloody mucous diarrhea and acute abdominal pain.

The diagnosis has been made after eliminating the parasitic, inflammatory and drug causes. This posed a diagnostic problem for us because of the non-specific symptoms associated with the lack of standardized histological criteria and the lack of clear, codified consensus regarding treatment.

\section{Introduction}

Eosinophilic colitis is a rare disease of the digestive tract characterized by abnormal infiltration of the colonic mucosa by eosinophilic polynuclear cells. Since 1979, only a few cases of eosinophilic colitis have been reported [1]. Its exact prevalence remains unknown, with a peak prevalence in newborns and young adults and without any gender preference [1].

The digestive symptomatology of eosinophilic colitis is highly variable and nonspecific; the clinical symptoms are dominated by diarrhea and abdominal pain. There is no histological consensus to make the diagnosis of eosinophilic colitis a polynucleareosinophils rate greater than 40 per high magnification field in at least two different colonic segments could be the criterion used for the diagnosis [2].

We present in this work the case of eosinophilic colitis in a 69-year-old man and we discuss in the light of data from the literature the diagnostic and therapeutic modalities of this rare and ambiguous entity.

\section{Case report}

We report the case of a 69-year-old man, operated 6 years ago for localized prostatic adenocarcinoma, without any other particular pathological history, in particular no history of atopic diseases, no known food or drug allergy and no recent trip. Admitted in a table of mucous-bloody diarrhea at a rate of 3-4 stools/day evolving for 5 days aggravated by the installation of acute abdominal pain evolving for less than 24 hours in a context of apyrexia and conservation of the general state. On clinical examination, the patient was hemodynamically and respiratory stable, temperature at $37.5^{\circ} \mathrm{C}$, maximum diffuse abdominal tenderness in the left iliac fossa, on rectal examination the finger cot came back soiled with stool and blood.

An abdominal CT scan was performed urgently objectifying a regular and circumferential parietal thickening of the descending colon, extended to the sigmoid loop, measuring $15 \mathrm{~mm}$ thick extended over $20 \mathrm{~cm}$ and obstructing the lumen in places, enhanced after injection of contrast product with hyperemia and infiltration of neighboring mesenteric fat. The free prostatectomy compartment without nodular lesions.

The biological blood test showed a predominantly eosinophilic hyperleukocytosis and the serum immunoglobulin E level assay was normal at 40KU/l $(\mathrm{N}<150 \mathrm{KU} / \mathrm{l})$. The results of the biological test represented in the following Table 1. 
A left colonoscopy performed with progression to the left colonic angle showing a fragile erythematous mucosa bleeding on contact with an interval of healthy mucosa, located in the descending colon of a large digging ulceration, staged biopsies were performed (Figure 1).

Anatomopathological study objective a subacute and chronic exulcerative and inflammatory reshuffles with a richness in eosinophils (more than 100 eosinophils $/ \mathrm{mm}^{2}$ ), architectural disorganization, without signs of specificity or malignancy (Figure 2).

The three coproparasitological examinations of stools returned negative.

In front of blood eosinophilia, the richness in eosinophils in the histological study of colonic biopsies, the negativity of the copro-parasitological examinations of the stool, and the absence of secondary causes of colonic eosinophilia, the diagnosis of eosinophilic colitis was retained and the management was to put the patient on corticosteroid therapy (prednisone) orally full dose at $1 \mathrm{mg} / \mathrm{kg} /$ day for 1 month then decrease over 8 weeks associated with a diet with avoidance of six foods (soy, wheat, eggs, milk, peanuts, shellfish) for 6 weeks then gradual re-introduction of each product.

Table 1: Results of biological tests.

\begin{tabular}{|c|c|c|}
\hline Figures of blood & Résults & Normal values \\
\hline Hémoglobin & $11 \mathrm{~g} / \mathrm{dl}$ & $14-16 \mathrm{~g} / \mathrm{dl}$ \\
\hline Platelets & $400.000 / \mathrm{UL}$ & $150-400(10 \star 3 / \mathrm{UL})$ \\
\hline White blood cells & $19.120 / \mathrm{UL}$ & $4-10(10 \star 3 / \mathrm{UL})$ \\
\hline Neutrophils & $3900 / \mathrm{UL}$ & $2-7(10 \star 3 / \mathrm{UL})$ \\
\hline Eosinophils & $9000 / \mathrm{UL}$ & $0.05-0.3(10 \star 3 / \mathrm{UL})$ \\
\hline Lymphocyts & $5380 / \mathrm{UL}$ & $0.9-5.2(10 \star 3 / \mathrm{UL})$ \\
\hline Inflammatory tests & & \\
\hline C reactive protein & 20 & $0-5$ \\
\hline sedimentation rate & 10 & Lower than 10 \\
\hline
\end{tabular}
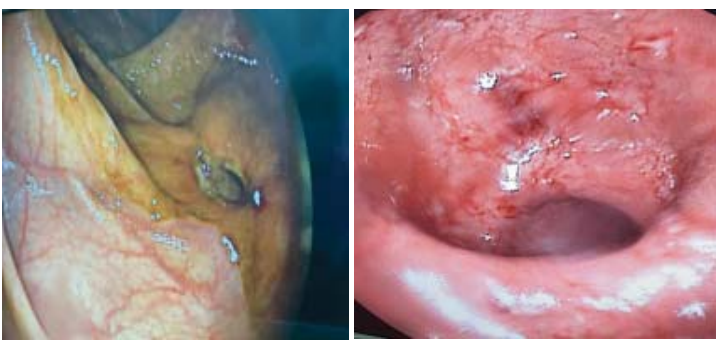

Figure 1: Erythematous colonic mucosa with digging ulceration.

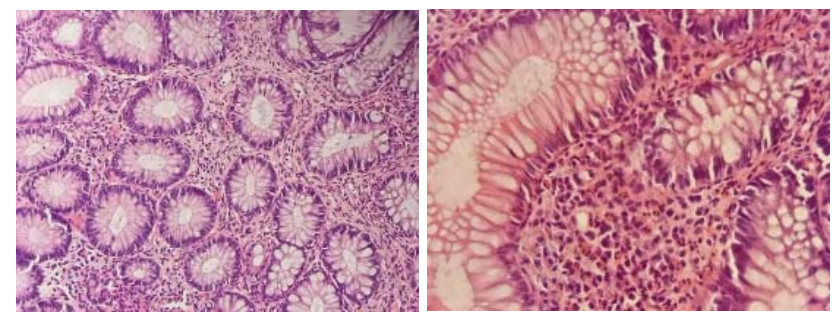

Figure 2: Eosinophilic infiltration of the colonic mucosa.
The evolution with the corticosteroid therapy and diet was favorable with disappearance of symptoms, especially diarrhea and abdominal pain from the first week of corticosteroid therapy. Biological check-up at the 2nd week of treatment showed a decrease in the level of blood eosinophils to 3350/UL.

A colonoscopy realized after 6 weeks of treatment revealed a colonic mucosa with a slightly erythematous appearance without ulcerations or process with histological study of colonic biopsies an eosinophil level of 20 Eosinophilis $/ \mathrm{mm}^{2}$.

\section{Discussion}

The accumulation of eosinophils in the digestive tract is a common phenomenon of several gastrointestinal pathologies, including IgE and non-IgE mediated food allergy (AA), eosinophilic esophagitis, eosinophilic gastritis, eosinophilic enteritis, eosinophilic colitis, Gastroesophageal Reflux Disease (GERD), drug reactions, parasitic infections, malignant diseases and inflammatory diseases of the digestive tract $[3,4]$.

Gastroenteritis and eosinophilic colitis represent an estimated incidence of 22 to 28 cases / 100,000 in the United States [5]. The exact pathogenesis of eosinophilic gastrointestinal disorders is not yet known. They probably result from a complex interaction between environment, genetics and immunological factors [6].

Several epidemiological studies suggest an allergic component, in particular food allergies, which elicits a Th2type immune response leading to the production of cytokines, such as interleukins, IL-4, IL-5, IL-13 and eotaxins-3. This results in intestinal eosinophilia, which further causes local inflammation by releasing toxic cationic proteins [7]. It can probably be both an IgE and non-IgE mediated disease [8].

The diagnosis of eosinophilic colitis is a diagnosis of exclusion, it is based on the association of non-specific gastrointestinal symptoms, the demonstration of an eosinophilic infiltration on the biopsies, and the exclusion of the causes secondary effects of eosinophilic infiltration such as parasitosis, drugs, chronic inflammatory digestive disease, malignant causes, autoimmune damage and hypereosinophilic syndrome $[8,9]$. There are no standardized histological criteria to make the diagnosis [1]. Imaging results are nonspecific and may show thickening of the colonic wall as well as ascites in some cases [10].

The treatment of eosinophilic enterocolitis remains a challenge in the absence of specific recommendations as there are no controlled trials to date on a specific treatment [11]. So far, the treatment of eosinophilic enterocolitis has been empirical and based on the severity of clinical manifestations, as well as the experience of clinicians. Patients with mild disease can be treated symptomatically, while more symptomatic patients and those with signs of malabsorption need more aggressive treatment [12].

A high proportion of cases of eosinophilic gastroenteritis are associated with food allergy. Therefore, diet therapy can improve symptoms [10]. It involves a "six-food elimination

Citation: Bouchrit S, Errami AA, Samlani Z, Oubaha S, Krati K (2021) Unusual cause of acute abdominal pain: Eosinophilic colitis case report and review of the literature. Arch Clin Gastroenterol 7(1): 015-017. DOI: https://dx.doi.org/10.17352/2455-2283.000091 
diet", avoiding milk, soy, eggs, wheat, peanuts, tree nuts and shellfish.

Corticosteroids are the optimal therapy for the induction of remission. Oral prednisone is the most common therapy, with an initial dose of $0.5-1 \mathrm{mg} / \mathrm{kg}$ and decreased over a period of 6-8 weeks. Relapses can occur and require low maintenance doses (1 to 10mg / day) of prednisolone [13] or the substitution of prednisolone by budesonide which has a better safety profile $[14,15]$.

Other therapies targeting immune modulation have been described in reports and small case series are likely to be helpful in treating recurrent or refractory symptoms. They include mast cell inhibitors such as cromolyn, ketotifen, leukotriene receptor antagonists, anti-IL-5 antibodies, omalizumab and anti-IgE monoclonal antibodies [12].

\section{Conclusion}

Our clinical case highlights a rare condition of the digestive tract which is often underdiagnosed. Eosinophilic colitis is rarely described and remains a diagnosis by exclusion, hence the need for further studies in order to better define the diagnostic criteria and the therapeutic attitude towards this rare and unknown entity.

\section{References}

1. Bates AWH (2012) Diagnosing eosinophilic colitis: histopathological pattern or nosological entity? Scientifica (Cairo) 2012: 682576. Link: http://bit.ly/3uYAOxJ

2. Gilles Macaigne (2018) Adult eosinophilic colitis. Hepato-Gastro \& Digestive Oncology 25: 792-802.

3. Rothenberg ME (2004) Eosinophilic gastrointestinal disorders (EGID). J Allergy Clin Immunol 113: 11-28. Link: http://bit.ly/3uUpVwP

4. Furuta GT, Forbes D, Boey C, Dupont C, Putnam P, et al. (2008) Eosinophilic Gastrointestinal Diseases Working Group. Eosinophilic gastrointestinal diseases (EGIDs). J Pediatr Gastroenterol Nut 47: 234-238. Link: http://bit.ly/3kKWcBP

5. Spergel JM, Book WM, Mays E, Song L, Shah SS, et al. (2011) Variation in prevalence, diagnostic criteria, and initial management options for eosinophilic gastrointestinal diseases in the United States. J Pediatr Gastroenterol Nutr 52: 300-306. Link: http://bit.ly/3ecACoC

6. Lopes Azevedo R, Pinto J, Ribeiro H, Pereira F, Leitão C, et al. (2018) Eosinophilic Enterocolitis: An Exceedingly Rare Entity. GE Port J Gastroenterol 25: 184-188. Link: http://bit.ly/30corzF

7. Cherian ET, Zhang HC, Guttenberg KB, Everett JM. Guha S (2018) Looking Beyond the Obvious: Eosinophilic Enterocolitis. Am J Med 131: e227-e229. Link: http://bit.ly/3c73FXI

8. Alfadda AA, Storr MA, Shaffer EA (2011) Eosinophilic colitis: an update on pathophysiology and treatment. $\mathrm{Br}$ Med Bull 100: 59-72. Link: https://bit.ly/3riL5CF

9. Samiullah, Bhurgri H, Sohail U (2016) Eosinophilic disorders of the gastrointestinal tract. Prim Care 43: 495-504. Link: http://bit.ly/3c3CUUf

10. Zhang M, Li Y (2017) Eosinophilic gastroenteritis: a state-of-the-art review. J Gastroenterol Hepatol 32: 64-72. Link: http://bit.ly/3uZOABJ

11. Uppal V, Kreiger P, Kutsch E (2016) Eosinophilic gastroenteritis and colitis: a comprehensive review. Clin Rev Allergy Immunol 50: 175-188. Link: http://bit.ly/3rnu2is

12. Sunkara T, Rawla P, Yarlagadda KS, Gaduputi V (2019) Eosinophilic gastroenteritis: diagnosis and clinical perspectives. Clin Exp Gastroenterol 12: 239-253. Link: http://bit.ly/3c7rD5c

13. Wong GW, Lim KH, Wan WK, Low SC, Kong SC (2015) Eosinophilic gastroenteritis: clinical profiles and treatment outcomes, a retrospective study of 18 adult patients in a Singapore Tertiary Hospital. Med J Malaysia 70: 232237. Link: http://bit.ly/2MQWxq4

14. Busoni VB, Lifschitz C, Christiansen S, GdD MT, Orsi M (2011) Eosinophilic gastroenteropathy: a pediatric series. Arch Argent Pediatr 109: 68-73. Link: http://bit.ly/38cfpHt

15. Lombardi C, Salmi A, Passalacqua G (2011) An adult case of eosinophilic pyloric stenosis maintained on remission with oral budesonide. Eur Ann Allergy Clin Immunol 43: 29-30. Link: http://bit.ly/3kMY7WI

\section{Discover a bigger Impact and Visibility of your article publication with} Peertechz Publications

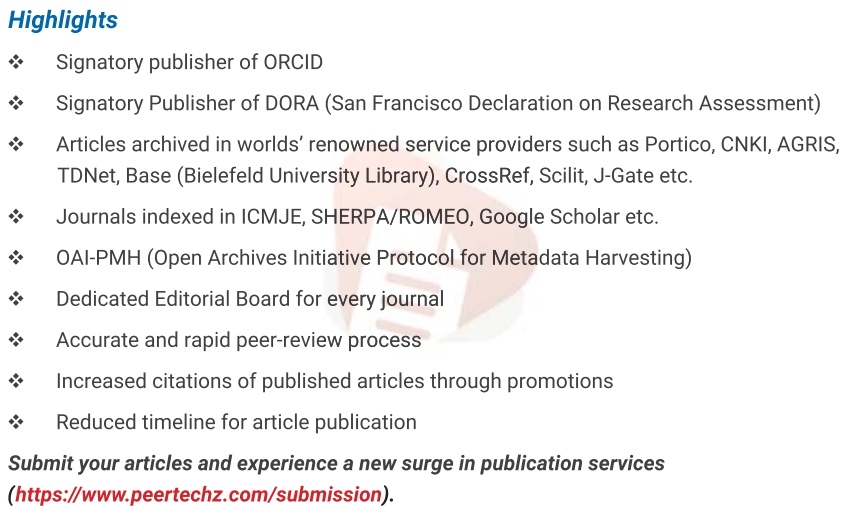

Peertechz journals wishes everlasting success in your every endeavours.

Copyright: @ 2021 Bouchrit S, et al. This is an open-access article distributed under the terms of the Creative Commons Attribution License, which permits unrestricted use distribution, and $r$ eproduction in any medium, provided the original author and source are credited. 